\title{
NILAI-NILAI RELIGIUSITAS DALAM NOVEL TASBIH CINTA DI LANGIT MOSKOW KARYA INDAH EL-HAFIDZ
}

\author{
Rina Melani Putri, Emi Agustina, dan Amril Canrhas \\ Program Studi Pendidikan Bahasa Indonesia \\ Jurusan Pendidikan Bahasa dan Seni \\ FKIP Universitas Bengkulu \\ rinamelaniputrinafri@gmail.com
}

\begin{abstract}
Abstrak
Tujuan penelitian ini adalah untuk mendeskripsikan nilai-nilai religiusitas dalam novel Tasbih Cinta di Langit Moskow karya Indah El-Hafidz. Penelitian ini merupakan penelitian kualitatif dengan menggunakan pendekatan Psikologi Sastra. Pendekatan ini digunakan untuk mendeskripsikan data-data dalam novel Tasbih Cinta di Langit Moskow yang berkaitan dengan nilai-nilai religiusitas. Langkah-langkah analisis data dalam penelitian ini yaitu: 1) Membuat sinopsis cerita novel Tasbih Cinta di Langit Moskow; 2) Menganalisis tema, tokoh/penokohan, alur, dan latar novel Tasbih Cinta di Langit Moskow; 3) Menganalisis nilai religiusitas dalam novel Tasbih Cinta di Langit Moskow; 4) Membuat kesimpulan hasil analisis dari novel Tasbih Cinta di Langit Moskow. Hasil pembahasan dalam penelitian ini yaitu didapatkan nilai religiusitas dalam novel Tasbih Cinta di Langit Moskow yang dicerminkan dalam bentuk: Keyakinan terhadap Tuhan, Tuhan tempat mengadu dan meminta pertolongan, selalu berdoa, berserah diri kepada Tuhan, hidup penuh syukur, melaksanakan kewajiban, memohon ampunan kepada Tuhan, serta menolong dan perduli terhadap ciptaan Tuhan. Penelitian ini menghasilkan kesimpulan yaitu diperoleh nilai-nilai religiusitas berupa keyakinan seorang hamba terhadap Tuhannya dan kecintaan seorang anak terhadap orangtuanya.
\end{abstract}

Kata kunci: Nilai-nilai religiusitas, novel

\begin{abstract}
The purpose of this research is to describe the religious values in "Tasbih Cinta di Langit Moskow" novelby Indah El-Hafidz. This research qualitative research by using Psychology approach to describe the data in "Tasbih Cinta di Langit Moskow" novel which related to religious values. The steps of analysis data, researcher used: 1) Making synopsis of novel story of Tasbih Cinta di Langit Moskow; 2) Analyzing theme, character / characterization, groove and background of novel Tasbih di Langit Moskow;3) Analyzing the values of religiosity in the novel Tasbih Cinta di Langit Moskow; 4) Draw up the results of the analysis of the novel Tasbih Cinta di Langit Moskow. The result of the discussion in this research is obtained the values of religiosity in the novel Tasbih Cinta di Langit Moskow which is reflected in the form of: Belief in God, God places complaints and asks for help, always pray, surrender to God, live gratefully, perform obligationsand help and care for God's creation. The result of this study isobtained the religious values in the people belief of God and a child's love of his parents.
\end{abstract}

Keywords: Religiosity values, novels 


\section{PENDAHULUAN}

Karya sastra diciptakan pada dasarnya bukan hanya sebagai hasil proses kreatif yang bersifat imajinatif saja, karya sastra juga dihadirkan oleh pengarang melalui latar belakang permasalahan kehidupan yang ada dalam masyarakat. Oleh karena itu, karya sastra sering disebut sebagai cerminan kehidupan manusia yang dikemas melalui bahasa dan ditambah dengan unsur imajinasi pengarang.

Secara etimologis kesusastraan berarti karangan yang indah. "Sastra" (dari bahasa sangsekerta) artinya: tulisan, karangan. Menurut Wellek dan Warren (2014: 3), sastra adalah suatu kegiatan kreatif, sebuah karya seni. Akan tetapi saat ini pengertian "kesusastraan" berkembang melebihi pengertian etimologis tersebut. Kata "indah" sangat luas maknanya, tidak hanya yang dapat dilihat oleh kasat mata, tetapi juga bisa dirasakan oleh pembaca.

Kemudian pendapat lain yang ikut menunjang argumen tersebut disampaikan Horace (dalam Ismawati, 2013: 3) bahwa sastra itu dulce et utile, artinya indah dan bermakna. Indah berarti karya sastra itu dapat dinikmati karena nilai estetikanya. Sedangkan bermakna berarti di dalam karya sastra tersebut terdapat nilai-nilai yang dapat dijadikan sebagai bahan pembelajaran oleh pembaca. Selain itu karena bermakna sastra juga berfungsi sebagai bahan renungan dan refleksi kehidupan karena sastra bersifat koeksistensi (berdampingan) dengan kehidupan.

Terdapat berbagai jenis karya sastra antara lain, karya sastra berbentuk prosa, puisi, drama, dan prosa liris. Sama halnya dengan puisi dan drama, prosa pun terbagi lagi ke dalam beberapa jenis di antaranya cerpen, novel, dan roman.

Novel merupakan salah satu genre prosa yang cukup banyak diminati selain cerpen. Dalam hal ini penulis memilih novel sebagai objek penelitian karena sebuah novel secara khusus memiliki peluang yang cukup luas untuk mempermasalahkan karakter tokoh dalam sebuah perjalanan waktu/kronologi, yang hal ini tidak mungkin dilakukan pengarang dalam prosa jenis cerpen. Kemudian pada novel juga terdapat permasalahan yang lebih kompleks sehingga dari permasalahan-permasalahan tersebut akan mengarah pada suatu klimaks yang merupakan puncak permasalahannya. Selain itu novel banyak menggambarkan refleksi kehidupan di dalam masyarakat, novel juga sarat akan nilai-nilai dan pesanpesan moral di dalamnya. Serta tidak hanya mementingkan keindahannya saja.

Menurut Sutomo (dalam Ismawati, 2013: 18) nilai adalah sebuah konsepsi abstrak yang menjadi acuan atau pedoman utama mengenal masalah mendasar dan umum yang sangat penting dan ditinggikan dalam kehidupan suatu masyarakat, bangsa, atau bahkan kemanusiaan. la menjadi acuan tingkah laku sebagian besar masyarakat bersangkutan, mengkristal dalam alam pikiran dan keyakinan mereka, cenderung bersifat langgeng, dan tidak mudah berubah atau tergantikan. Salah satu nilai penting yang terdapat dalam sebuah karya sastra adalah nilai religiusitas, sebab pada awal mulanya segala sastra adalah religius (Mangunwijaya, 1982: 11).

Menurut Mangunwijaya (1982: 11), religiusitas lebih melihat aspek yang "di dalam lubuk hati", riak getaran hati nurani pribadi, sikap personal yang sedikit banyak merupakan misteri bagi orang lain, karena menapaskan intimitas jiwa, dan cita rasa yang mencakup totalitas (termasuk rasio dan rasa manusiawi) ke dalam si pribadi manusia.

Sejalan dengan penjelasan di atas maka tujuan pengarang dalam membuat sebuah karya sastra terutama novel yaitu untuk menyampaikan nilai-nilai dan norma-norma yang ada di dalam novel, 
yang diharapkan dapat memberikan hal positif dan perubahan baik serta dapat diterapkan di kehidupan sehari-hari pembaca. Seperti salah satu novel yang berjudul Tasbih Cinta di Langit Moskow Karya Indah El Hafidz ini, pada novel ini pengarang menceritakan mengenai seorang anak perempuan yang awalnya memeluk agama sesuai dengan keyakinan papanya. Namun setelah papanya menikah lagi ia memutuskan untuk ikut bersama Mamanya dan memilih untuk tidak memeluk agama Islam, sebab menurut Bonnieta Islam berpihak kepada kaum lakilaki sedangkan kaum perempuan tertindas. Walaupun demikian Bonnieta tidak memeluk Kristen Ortodoks seperti Mamanya sebab dia yakin dan percaya kepada Allah SWT Tuhan umat Islam. Hal inilah yang menjadi alasan penulis memilih nilai-nilai religiusitas sebagai aspek yang akan penulis kaji, sebab di dalam novel ini menjelaskan mengenai nilai-nilai tersebut baik yang tersurat maupun yang tersirat. Sedangkan penulis memilih novel Tasbih Cinta di Langit Moskow sebagai objek penelitian karena novel ini belum banyak yang menelitinya, selain itu penulis belum menemukan penelitian yang mengambil dari nilai religiusitasnya. Selain itu, bahasa yang digunakan dalam novel ini juga cukup mudah untuk dipahami oleh pembaca, hanya saja terdapat sedikit istilah asing yang digunakan, hal itu sesuai dengan lokasi yang diceritakan pengarang yaitu di Moskow dan Alexandria.

Kemudian alasan yang menujang penulis ingin melakukan penelitian ini karena semakin banyak kebudayaan luar yang masuk dan dengan berkembangnya teknologi dikhawatirkan dapat merusak moral dan mempengaruhi kepercayaan yang telah dianut oleh seseorang baik melalui bahan bacaan maupun interaksi yang dilakukan secara langsung. Untuk itu penting dengan adanya bahan bacaan yang bermutu yang dapat memberikan pendidikan khususnya nilai religiusitas kepada masyarakat atau pembaca, sehingga setidaknya melalui bahan bacaan ini mampu memberikan sedikit jawaban atau solusi dalam persoalan yang timbul di masyarakat. Hadirnya novel yang mengandung nilai-nilai religiusitas diharapkan mampu meningkatkan kembali moral masyarakat yang semakin menurun.

Selain itu konflik yang terjadi dalam novel juga terjadi pada kehidupan nyata yaitu kesadaran sosial dan rasa empati manusia yang saat ini semakin memudar diakibatkan sifat individualis yang merujuk kepada menurunnya nilai religiusitas yang seharusnya tertanam pada diri setiap manusia.

Untuk itu pada penelitian ini penulis akan menganalisis nilai-nilai religiusitas dengan objek penelitian novel Tasbih Cinta di Langit Moskow dengan judul "Nilai-nilai Religiusitas dalam Novel Tasbih Cinta di Langit Moskow karya Indah El Hafidz".

\section{METODE}

Metode yang digunakan dalam peneltian ini adalah metode deskriptif kualitatif yang bertujuan untuk mendeskripsikan dan menganalisis nilainilai religiusitas dalam novel Tasbih Cinta di Langit Moskow karya Indah El Hafidz. Kemudian nilai-nilai religiusitas dalam novel Tasbih Cinta di Langit Moskow ini akan dianalisis menggunakan pendekatan psikologi sastra yang berfokus pada teks. Di mana pendekatan psikologi sastra ini hanya mengacu pada teks atau pilihan kata yang digunakan pengarang dalam karya sastra. Dengan menggunakan pendekatan ini, nilai-nilai religiusitas dalam novel Tasbih Cinta di Langit Moskow akan dianalisis berdasarkan tema, tokoh/ penokohan, alur dan latar. Sehingga penulis bisa menentukan nilai-nilai religiusitas apa saja yang terdapat pada novel ini. 
Data dalam penelitian ini, data berupa hasil pencatatan kalimat-kalimat yang ada di dalam novel Tasbih Cinta di Langit Moskow karya Indah El Hafidz yang mengandung nilai-nilai religiusitas. Dan sumber data dalam penelitian ini adalah novel Tasbih Cinta di Langit Moskow karya Indah El Hafidz yang diterbitkan oleh Naura Novel pada tahun 2014 dengan jumlah halaman 272. Teknik pengumpulan data yang akan digunakan pada penelitian ini adalah teknik studi pustaka. Studi pustaka dilakukan untuk mendapatkan bahanbahan dan informasi yang berhubungan dengan penelitian seperti buku-buku, artikel, dan dokumen-dokumen lain yang berhubungan dengan penelitian.

Teknik analisis data yang digunakan dalam penelitian ini adalah model analisis konten (Content Analysis), Analisis konten merupakan strategi untuk menangkap pesan dalam sebuah karya sastra. Adapun langkah-langkah analisis data yang digunakan dalam penelitian ini yaitu: 1) Membaca novel Tasbih Cinta di Langit Moskow karya Indah El Hafidz secara keseluruhan, 2) Membuat sinopsis cerita dari novel Tasbih Cinta di Langit Moskow karya Indah El Hafidz, 3) Menganalisis tema, tokoh/ penokohan, alur dan latar, 4) Menganalisis nilai-nilai religiusitas dalam novel Tasbih Cinta di Langit Moskow karya Indah El Hafidz, 5) Membuat kesimpulan tentang nilai-nilai religiusitas yang ada di dalam novel Tasbih Cinta di Langit Moskow karya Indah El Hafidz.

\section{HASIL PENELITIAN DAN PEMBAHASAN Hasil Penelitian}

Tema novel Tasbih Cinta di Langit Moskow karya Indah El-Hafidz yaitu tentang keyakinan seorang hamba terhadap Tuhannya dan cinta seorang anak terhadap orang tuanya. Novel Tasbih Cinta di Langit Moskowini menampilkan beberapa tokoh diantaranya : Bonnieta, Miss Sahira, Mama (Caroline), Kakek
Victor, Antonio, Kak Adnan/Khiar, Joseph, Ayah, Sergei, Nenek Yeltsin, Kakek Suhendra, Teman Bonnieta di Moskow (Sofia, Zarkas, Samuel, Parlova), Ruskoi Medvedev, Jollie dan Karren (Orang Kepercayaan Caroline), Paman Abbas, Madam Corsova. Penggambaran para tokoh novel Tasbih Cinta di Langit Moskow dilukiskan secara langsung oleh pengarangnya yaitu dengan menguraikan keadaan lahiriah maupun batiniah para tokoh.

Secara sederhana alur pada novel ini di awali dengan pemaparan atau tahap penyituasian yaitu pengarang mulai menggambarkan keadaan cerita awal yang dialami para tokoh. Pada awal diceritakan sedikit mengenai masa lalu tokoh Bonnieta lewat sebuah mimpi, namun selanjutnya menceritakan bagaimana kehidupannya setelah berpisah dari Sang ayah dan hidup bersama Mama yang berprofesi sebagai desainer.

Dilanjutkan dengan tahap pemunculan konflik, yaitu pengarang mulai melukiskan peristiwa-peristiwa yang menyulut terjadinya konflik antara para tokoh yang terlibat dalam cerita. Tokoh tersebut yaitu Bonnieta atau Aisha, Mama Bonnieta, Miss Sahira, Kak Adnan, Kakek Victor, Antonio, dan lain-lain. Bagian ini juga murupakan bagian cerita mulai bergerak dan terjadi konfik antar tokoh. Salah satunya ketika ada seorang laki-laki yang mengambil foto Bonnieta dan Mamanya secara diam-diam ketika mereka keluar apartemen untuk berbelanja.

Kemudian tahap peningkatan konflik yaitu pengarang melukiskan konflikkonflik yang dialami para tokoh mulai memuncak. Konflik-konflik tersebut mulai memuncak ketika terjadi perdebatan antara Bonnie dan Mamanya mengenai kakek Victor. Mama Bonnie sangat membenci kakek Victor, entahlah kesalahan apa yang diperbuat kakek Victor padahal dia adalah orangtua kandung 
Mama. Berbeda dengan Mamanya Bonnie sangat menyanyai kakek Victor. Ditambah lagi setelah perdebatan itu reda, tiba-tiba bel apartemen berbunyi, tak ada siapasiapa hanya ada surat berwarna merah jambu yang ditujukan untuk Bonnie yang berisikan permintaan maaf Antonio kepada Bonnie atas kematian Joseph kekasih Bonnie. Karena Antoniolah yang menaruh racun dalam vodka Joseph, tetapi hal itu dilakukanya demi Bonnie sebab Joseph memiliki recana jahat terhadap Bonnie. Seketika kata-kata dalam surat itu seperti ribuan jarum yang menusuk Bonnie, apalagi dalam surat itu Antonio mengatakan bahwa yang ia lakukan itu karena sebenarnya Joseph tidak benarbenar mencintai Bonnie tetapi ia hanya ingin balas dendam sebab Mama Bonnie memiliki skandal dengan ayah Joseph. Sehingga Joseph ingin menghancurkan hidup Bonnie dan merusak masa depan Bonnie.

Selanjutnya tahapan klimaks, dalam bagian ini banyak sekali permasalahan yang dialami tokoh utama. Cobaan yang dialami Bonnieta sangat bertubi-tubi ia harus menerima kenyataan bahwa memang benar Mamanya berselingkuh dengan ayah Joseph. Dan Joseph mendekati Bonnie hanya untuk balas dendam sebab di Moskow hanya Bonnie yang Mamanya miliki. Ditambah lagi sejarah kehidupan sang Mama yang sangat memilukan yang menjadi alasan mengapa Mama sangat membenci kakek Victor. Hal itu karena kakek Victor adalah mantan mafia dan Mamalah yang menjadi korban hingga kehidupan Mama saat itu sangat ironis dan tragis. Batin Bonnieta semakin hancur ketika harus menerima kenyataan bahwa sang Mama yang sangat ia sayangi meninggal dunia padahal ia tak sempat bertemu Mamanya untuk terakhir kalinya.

Terakhir tahap penyelesaian, lakilaki yang Bonnie temui dirumah kakek Victor ternyata adalah kakaknya Adnan dan dia lah yang mendampingi sang Mama hingga Mama Bonnieta meninggal dalam keadaan Islam (menyebut Syahadat), sebelum meninggal sang Mama menitipkan surat yang berisikan agar Bonnie kembali menjadi Aisha kecil berkerudung dan kembali kepelukan sang papa (tinggal di Alexandria). Di sisi lain, Antonio telah menyerahkan diri ke polisi dan mengakui kesalahannya setelah Bonnie memaafkannya. Antonio orang yang sangat Bonnie benci justru orang yang sangat mencintainya, benar-benar mau melindungi Bonnie dan orang yang rela mengorbankan masa depannya demi Bonnie. Berdasarkan penjelasan dan pemaparan di atas, maka alur pada novel Tasbih Cinta di Langit Moskow ini berupa alur progresif karena menceritakan rangkaian peristiwa secara kronologis dari yang paling awal hingga akhir secara runtut.

Kemudian dalam novel ini Moskow menjadi tempat sekaligus saksi kehidupan Bonnieta semenjak perceraian antara Mama dan Papanya, Bonnie memilih untuk ikut dengan Mamanya di Moskow dan meninggalkan Alexandria begitu juga dengan Papa dan Kakak laki-lakinya.

\section{Pembahasan}

Berdasarkan identifikasi yang penulis lakukan berkaitan dengan nilai-nilai religiusitas yang terdapat dalam novel Tasbih Cinta di Langit Moskow karya Indah El-Hafidz adalah sebagai berikut:

a) KeyakinanTerhadapTuhan.

Tokoh Bonnie adalah sosok orang yang teguh pendirian dan percaya kepada Allah, sehingga ia menolak keinginan sang mama untuk dibaptis. Hal itu terlihat pada kutipan berikut ini.

"Di sisi lain, sejak kecil Aku yakin Allah sebagai Tuhan sehingga Aku selalu menolak ajakan Mama untuk dibaptis di gereja agar mengikuti 
keyakinan Mama. Bagiku, agama dan keyakinan adalah hak paling dasar dalam diri seseorang. Tidak ada paksaan untuk mengikuti suatu agama tertentu, dengan alasan apapun." (El-Hafidz, 2014:13-14).

Kutipan di atas menggambarkan sosok Bonnie yang teguh pendirian, apalagi mengenai keyakinan. Karena agama dan keyakinan merupakan sesuatu yang tidak bisa dipaksakan dengan alasan apapun sebab setiap orang berhak memilih apa yang mereka yakini tanpa unsur paksaan. Dan keyakinan itu berasal dari hati masingmasing orang. Sehingga nilai religiusitas yang diperoleh yaitu sebagai makhluk ciptaan Tuhan seharusnya kita percaya terhadap Sang Pencipta karena Allah lah yang menciptakan langit dan bumi beserta isinya. Keyakinan ini tentunya terdapat pada hati setiap orang dan hal tersebut tentu tak bisa dipaksakan. Karena kayakinan itu berasal dari hati manusia.

\section{b) Tuhan Tempat Mengadu dan Meminta Pertolongan.}

Tokoh Bonnieta mengalami kejadian dimana dia harus menerima kenyataan bahwa ternyata kekasihnya tewas akibat diracuni oleh temannya sendiri. lapun tak mampu berbuat apa-apa selain meminta pertolongan Allah.

"...... Mendengar itu, tubuhk umenggigil, serasa ada hawa dingin yang menggesek. Tuhan, aku yakinTuhan mendengarnya (ElHafidz, 2014: 72).

Kutipan di atas menunjukkan bahwa Bonnieta percaya Allah Maha Melihat dan Maha Mendengar, apa yang dilakukan manusia dan hanya kepada Allah lah tempat memohon pertolongan karena Allah lah Dzat Maha Kuasa.Berdasarkan pemaparan itu, maka nilai religiusitas yang dapat diambil yaitu Tuhan tempat mengadu dan meminta pertolongan karena dalam menjalani kehidupan tentu banyak sekali cobaan dan rintang yang dialami seorang. Untuk itu seorang hamba akan mengadu dan miminta pertolongan Allah saat mereka tak mampu berbuat apaapa sebab Allah adalah Dzat Maha Kuasa dan Maha memberi Pertolongan.

\section{c) Selalu Berdoa.}

Mama merupakan anugrah dari Tuhan yang sangat Bonnie sayangi. Bonnie berdoa kepada Tuhan agar ia bisa selalu bersama sang mama dan membuat mamanya bahagia.

"Mama .... Aku sangat ingin melihat senyum menawan itu dari sudut pipi Mama. Sekarang, nanti, dan selamanya, Amin, ya Tuhan...." (ElHafidz, 2014:19).

Kutipan di atas menunjukkan bahwa ketika seorang manusia ingin berharap maka berharaplah hanya kepada Tuhan, Berdoa, mintalah pertolongannya karena tak ada yang tidak mungkin. Agar orang-orang yang kita sayangi selalu dalam lindungan-Nya sama halnya dengan yang dilakukan Bonnieta.Dari pemaparan itu, maka nilai religiusitas yang dapat diambil yaitu berserah diri kepada Tuhan, karena Tuhan merupakan Dzat yang Maha Berkehendak atas segala hal. Jika Tuhan sudah berkehendak maka tak ada hal yang mustahil untuk terjadi. Dan Allah mampu membolak-balikan hati para hamba yang dikehendaki-Nya.

Peristiwa mengenai kematian Joseph memang sempat membuat Bonnie sangat membenci Antonio, tapi setelah Bonnie tau kebenarannya Bonnie baru menyadari bahwa orang yang sangat mencintainya itu adalah Antonio, dia rela mengorbankan massa depanya demi Bonnie. Jika saja Antonio memiliki keyakinan yang sama dengan Bonnie tentu Bonnie tak hanya mendampingi Antonio ketika persidangan, tapi sepanjang hidupnya. 
"Aku menyodorkan sebuah buku tentang sejarah Islam. Aku tak memaksanya memeluk Islam. Namun, jika Allah sudah menghendaki kami bersatu, aku yakin hati Antonio akan tergugah untuk bersyahadat (El-Hafidz, 2014:255).

Dari kutipan di atas menunjukkan bahwa sebagai manusia seharusnya kita hanya berharap kepada Allah, menyerahkan kepada-Nya karena Allah akan memberikan yang terbaik. Bonnietapun melakukan hal demikian, ia tak memaksa Antonio untuk memeluk Islam sepertinya, tapi ia yakin jika Allah menghendaki mereka bersatu maka Antonio akan tergugah hatinya untuk bersyahadat. Dari pemaparan itu, maka nilai religiusitas yang dapat diambil yaitu berserah diri kepada Tuhan, karena Tuhan merupakan Dzat yang Maha Berkehendak atas segala hal. Jika Tuhan sudah berkehendak maka tak ada hal yang mustahil untuk terjadi. Dan Allah mampu membolak-balikan hati para hamba yang dikehendaki-Nya.

d) Hidup Penuh Syukur.

Bonnie sangat senang ketika tahu bahwa sang mama ingat akan hari ulang tahunnya. Walaupun Bonnie tak pernah memikirkan ulang tahun. Karena bersama mama adalah perayaan terindah, jauh lebih indah dari sekedar ulang tahun.

"Bersama linangan air mata dan rasa syukur yang luar biasa, kepeluk Mama. Kepeluk erat tubuh wanita yang sangat kusayang itu. Mama, saat ini hanyalah Mama yang kupunya. Tiada yang lebih membahagiakan selain bisa bersama Mama selamanya. Mama adalah insan paling berharga yang dikirim Tuhan untukku" (El-Hafidz, 2014:12).

Berdasarkan kutipan di atas, tokoh Bonnieta dicerminkan sebagai seorang anak yang menyayangi orangtuanya, dan ia memiliki keyakinan bahwa sang Mama merupakan anugrah yang diberikan Sang pencipta untuk dirinya untuk itu ia sangat bersyukur.Karena bersama mama adalah perayaan terindah, jauh lebih indah dari sekedar ulang tahun. Dari pemaparan itu, maka nilai religiusitas yang dapat diambil yaitu hidup penuh syukur. Sebab bersyukur merupakan salah satu bentuk terimakasih terhadap nikmat dan karunia yang diberikan Sang Pencipta. Karena manusia tak akan mampu menghitung berapa banyak nikmat yang telah Allah berikan. Walaupun itu tak sesuai dengan yang kita inginkan tetapi Allah lebih tau apa yang terbaik untuk hambanya.

e) Melaksanakan Kewajiban.

Tokoh Miss Sahira, dalam novel ini ditampilkan sebagai sosok yang taat kepada Allah. Walaupun Islam termasuk golongan minoritas di Moskow, namun hal itu tak lantas membuatnya lalai akan kewajibannya terhadap Allah.Tokoh Miss Sahira, dalam novel ini ditampilkan sebagai sosok yang taat kepada Allah. Walaupun Islam termasuk golongan minoritas di Moskow, namun hal itu tak lantas membuatnya lalai akan kewajibannya terhadap Allah.

"Allahu Akbar.., Kuikuti gerakan iman yang mengangkat kedua tangan sembari takbir, mengisyaratkan segala urusan dunia harus terhenti demi menghadap sang Khalik. Kami semua khusyuk dalam sholat magrib (El-Hafidz, 2014:105).

Dari kutipan di atas menunjukkan bahwa dalam ajaran agama Islam, ketika sholat seorang hamba harus mengerjakannya secara khusuk dan sholat merupakan kewajiban yang harus dikerjakan umat Islam. Karena ketika seseorang sholat maka tak ada jarak antara Allah dan hambanya itu. Dan saat sholat jugalah waktu yang baik untuk seorang 
hamba berdoa kepada Allah.Berdasarkan pemaparan itu maka, nilai religiusitas yang dapat diambil yaitu melaksanakan kewajiban. Karena semua agama mengajarkan para penganutnya untuk melaksanakan kewajibannya. Dan tentu dalam setiap agama pasti berbeda, walaupun demikian itu semua demi mewujudkan ketaatannya kepada Sang Pencipta.

\section{f) Mengakui Kebesaran Tuhan.}

Paman Abbas adalah seorang pendeta yang mendapat petunjuk dari Allah melalui gugusan bintang, setelah sebelumnya bertemu dengan seorang gadis remaja yang hendak dibaptis tibatiba menyerukan jika Yesus bukanlah Tuhan, melainkan utusan Tuhan.

"Beberapa menit kemudian, paman abbas mengeluarkan ponselnya. Ia memperlihatkanku sebuah gambar. Aku tersentak. Mendadak sekujur tubuhku gemetar. Ya Allah, apa yang kulihat di layar HP paman Abbas memang merupakan sebuah gugusan bintang yang membentuk asma Allah, Ar-Rahman yang artinya Maha Pengasih. Ini ajaib! Ini sungguh sangat ajaib! Aku mengatur hembusan nafasku"(El-Hafidz, 2014:170).

Kutipan di atas menunjukkan bahwa Allah memberikan hidayah kepada orangorang yang ia kehendaki. Seperti yang terjadi pada Pendeta Immanuel yang beberapa kali melihat pertanda alam di langit berupa gugusan bintang yang bertuliskan Ar-Rahman yang awalnya ia bingung itu apa hingga akhirnya ia memutuskan untuk mempelajari Al-qur'an dan memutuskan untuk menjadi seorang Muslim.Berdasarkan pemaparan itu, maka nilai religiusitas yang dapat diambil adalah mengakui kebesaran Tuhan. Tuhan merupakan Dzat Maha Kuasa, tak ada yang melebihi-Nya sebab Allah yang menciptakan langit, bumi beserta isinya. Maka jika Allah sudah berkehendak maka tak ada yang mampu mengubah takdirNya.

g) Memohon Ampunan kepada Tuhan.

Miss Sahira adalah orang yang taat dalam beribadah, namun tentu manusia tak luput dari kesalahan. Untuk itu sebagai seorang makhluk kita harus senantiasa mendekatkan diri dan memohon ampunan-Nya.

"Astaghfirullahalazim..... Aku menghela napas. Tiba-tiba aku ingat pesan almarhum ibu, Ketika hendak melakukan kebaikan, janganlah melakukanya karena seseorang melainkan karena Allah".

Ya Rabb.... aku takut jika niatku bergabung di organisasi kemanusian itu karena pemuda mesir tersebut, bukan semat-mata karena Allah.

(El-Hafidz, 2014: 90).

Kutipan di atas menunjukkan bahwa kita harus selalu beristighfar kepada Allah, terlebih jika kita merasa melakukan kesalahan atau kekeliruan. Sebab apapun yang diperbuat seseorang seharusnya hanya karena Allah, tidak boleh karena manusia.Hal itu menunjukkan bahwa tak ada kata terlambat untuk seseorang ingin bertobat. Sebab Allah adalah Zat yang Maha Pengampun, Allah akan mengampuni setiap hamba yang ingin bertobat dan kembali ke jalan-Nya. Itulah yang disampaikan Miss Sahira kepada Bonnieta agar ia tak ragu untuk bertobat. Dari pemaparan itu, maka nilai religiusitas yang dapat diambil yaitu selalu memohon ampunan. Sudah seharusnya sebagai seorang hamba tak henti-hentinya kita memohon ampun kepada Allah. Sebab manusia adalah orang yang lalai dan sering kali melakukan perbuatan yang tak disukai Allah. Dan hendaknya ketika menyadari hal tersebut sebagai hamba yang bertaqwa 
sudah seharusnya kita segera memohon ampunan.

\section{h) Menolong dan Peduli Terhadap Ciptaan Tuhan.}

Sebagai sesama makhluk ciptaan Tuhan sudah seharusnya saling menjaga, membantu, dan saling mengasihi. Tokoh Bonnieta digambarkan sebagai sosok orang yang memiliki rasa kemanusiaan dan empati yang tinggi terlebih terhadap negara Palestina.

"Palestina, Miss? Aku tertarik pada Negara tersebut. Suatu saat, aku akan terbang kesana untuk menjadi relawan. Subhanallah, sungguh niat yang lua rbiasa.Semoga Allah memberi jalan...." (El-Hafidz, 2014: 65).

Kutipan di atas menunjukkan bahwa perbedaan agama tak menjadi penghalang untuk kita berbuat baik, seperti yang Bonnieta ia ingin menjadi relawan untuk Palestina itu berdasarkan hati nurani dan rasa kemanusiaan yang ia miliki sehingga hatinya tergerak untuk membantu orang-orang di Palestina yang berjuang di jalan Allah melawan para Zionis Israel.Berdasarkan pemaparan itu, maka nilai religiusitas yang dapat diambil yaitu tolong-menolong dan peduli terhadap sesama makhluk ciptaan Tuhan. Karena Allah mengajarkan kita untuk menjaga hubungan baik antar sesama. Hal itu tentu diwujudkan dalam bentuk yang berbeda salah satunya dengan membantu mereka yang membutuhkan pertolongan. Sebab ketika kita memiliki kepedulian terhadap orang lain maka kita telah menanamkan rasa kemanusian dalam diri kita, dan Allah sangat menyayangi orangorang perduli terhadap sesama dan tolong menolong dalam hal kebaikan.

Itulah bentuk nilai-nilai religiusitas yang terdapat pada novel Tasbih Cinta di Langit Moskow. Nilai-nilai tersebut yaitu keyakinan terhadap Tuhan, Tuhan tempat mengadu dan meminta pertolongan, selalu berdoa, berserah diri kepada Tuhan, hidup penuh syukur, melaksanakan kewajiban, mengakui kebesaran Tuhan, memohon ampunan kepada Tuhan, serta menolong dan peduli terhadap ciptaan Tuhan. Semua nilai itu merupakan bentuk perasaan batin yang ada hubungannya dengan Tuhan, yang merupakan cerminan nilai religiusitas yang terdapat pada novel Tasbih Cinta di Langit Moskow.

\section{PENUTUP \\ Kesimpulan}

Berdasarkan hasil analisis yang telah dilakukan pada novel Tasbih Cinta di Langit Moskow karya Indah El-Hafidz dapat disimpulkan sebagai berikut:

a) Tema novel Tasbih Cinta di Langit Moskow karya Indah El-Hafidz ini yaitu mengenai keyakinan seorang hamba terhadap Tuhannya dan kecintaan seorang anak kepada orang tuanya. Selain itu, jalan cerita yang digunakan berupa alur maju. Di mana tokoh Bonnie yang awalnya seorang Agnostik, sekarang kembali menjadi seorang Muslim dan hal itu berdasarkan keyakinan dan kemantapan hatinya sendiri tanpa ada unsur paksaan dari pihak manapun. Walaupun ia tinggal di Moskow dengan gaya hidup sebagai remaja Eropa namun hal tersebut tak lantas mengubah keyakinannya terhadap Allah.

b) Nilai-nilai religiusitas pada novel Tasbih Cinta di Langit Moskow ini yaitu mengenai keyakinan seorang hamba terhadap Sang Pencipta (Tuhan) sehingga melalui keyakinannya itu, hanya Tuhan tempatnya mengadu dan meminta pertolongan, hal itu diwujudkan dengan cara selalu berdoa, berserah diri kepada Tuhan, hidup penuh syukur, melaksanakan kewajiban, mengakui kebesaran Tuhan, memohon 
ampunan kepada Tuhan, serta menolong dan peduli terhadap ciptaan Tuhan.

\section{Saran}

Novel Tasbih Cinta di Langit Moskow karya Indah El-Hafidz ini masih banyak hal-hal yang belum dituliskan dalam skripsi ini sebab penulis membatasi penelitian ini pada aspek religiusitasnya saja. Oleh karena itu, saya mengharapkan kepada para pembaca untuk meneliti halhal yang belum terungkap dalam skripsi ini, salah satunya dari nilai-nilai sosialnya.

\section{DAFTAR PUSTAKA}

Hafidz, Indah El. 2014. Tasbih Cinta di Langit Moskow. Jakarta: Noura Books.

Ismawati, Esti. 2013. Pengajaran Sastra. Yogyakarta: Ombak.

Mangunwijaya, Y.B. 1982. Sastra dan Religiositas. Jakarta: Sinar Harapan.

Wellek, Rane dan Austin Warren. 2014. Teori Kesusastraan. Jakarta: PT Gramedia Pustaka Utama. 